\title{
25 Research Square \\ Exploring perspectives on COVID-19 risk, protective behavior and control measures
}

\author{
Karwan M Amen \\ Hawler Medical University \\ Kazhan I. Mahmood \\ Hawler Medical University \\ Sherzad A. Shabu \\ Hawler Medical University \\ Nazar Shabila ( $\nabla$ nazarshabila@gmail.com ) \\ Hawler Medical University https://orcid.org/0000-0002-8921-195X
}

\section{Research article}

Keywords: COVID-19, Perspectives; Risk, Protective behavior, Prevention

Posted Date: April 24th, 2020

DOl: https://doi.org/10.21203/rs.3.rs-23554/v1

License: (9) This work is licensed under a Creative Commons Attribution 4.0 International License. Read Full License 


\section{Abstract \\ Background}

Understanding the public perception and behavior towards the spread of the coronavirus disease (COVID19) can help in mitigating the transmission of the infection. This study aimed to assess the perspectives of the people towards COVID-19, especially concerning the risk of the disease, adherence to protective measures, and the effectiveness of the imposed prevention and control measures.

\section{Methods}

An explorative study based on Q-methodology was conducted in Erbil, Iraqi Kurdistan Region. The study involved a purposively selected sample of 40 persons representing different educational, social, and economic levels. Forty-one statements were extracted that have covered various aspects of the impact of COVID-19 on the life of people, and different perceptions and uncertainties around it. We asked the participants to rank-order the 41 statements into a distribution on a nine point scale, ranging from "least agree" to "most agree." Data analysis involved a by-person factor analysis using PQMethod 2.35, which aimed to identify the main viewpoints.

\section{Results}

The analysis revealed three distinct viewpoints and one consensus perspective for the people's perspectives about COVID-19. Viewpoint 1, confidence and obedience to protective measures, centers on compliance with the main protective measures, the seriousness of COVID-19, and the effectiveness of the government's preventive measures. Viewpoint 2, apprehensiveness and noncompliance, focuses on extremely worry about the disease and concerns about the government measures against COVID-19. Viewpoint 3, people's inattentiveness, emphasizes the lack of awareness and adherence to protective measures by the people and ineffectiveness of the government's preventive measures.

\section{Conclusion}

The primary aspects distinguishing the three viewpoints focus on risk perception, protective behavioral response, and government's preventive measures. Risk perception can guide appropriate protective behavior, but not always. For strengthening the preventive measures, and compliance with protective behaviors, different approaches that can address the needs of different groups of people are required. The focus should be on increasing the risk awareness, reducing anxiety, and explaining the justification and effectiveness of the government's preventive measures.

\section{Introduction}


The novel coronavirus disease [SARS-CoV-2] first emerged in China in December 2019. The coronavirus disease (COVID-19) has later become an outbreak that was rapidly spreading in many other parts of the world and was officially announced as an emergency from the public health perspective [1].

People who get infected with the novel coronavirus will mainly develop some degrees of respiratory symptoms. Most of these people can recover without the need for any medical intervention or treatment. The disease mostly spread when the affected person sneezes or coughs through the nasal discharge and the saliva droplets [2].

Currently, there is no vaccine to protect people from COVID-19. Therefore, avoiding the exposure is so far the most suitable way to avoid infection. Person-to-person spread is the main way of getting infected. People need to follow some personal protective measures like avoiding close contact with sick people, social distancing, frequent hand washing, respiratory hygiene by covering mouth and nose while coughing and sneezing, staying home, wearing a face mask when feeling sick, and frequently clean and disinfect touched surfaces [3].

Most of the health behavior theories include components about potential harm beliefs or what is called risk perception. However, the closeness of the association between perception and behavior is still unclear. A better understanding of this association can help in guiding the development of the prevention programs, especially in the status of an epidemic [4]. However, people's behavior during a state of an epidemic is probably influenced by the degree of perceived risk, although these people might, on many occasions, lack the ability to perceive such a risk [5].

For the COVID-19 outbreak, the measures of containment have been considering case identification and management, isolation of the positively tested individuals, tracing and quarantining of the surrounding close contacts, and encouraging precautionary behaviors among the general population. Coinciding with these measures, most of the governments are closing schools and extending public holidays, and besides that, people are facing rather confusing information about the newly emerging viral infection. As a result, the control of this outbreak can be considerably influenced by the behavioral and psychological responses of the general public [6].

The adherence of people to the preventive and control measures is very crucial to ensure the mitigation of the spread of this epidemic, and this is greatly affected by the people's level of knowledge, attitude, and practices towards COVID-19 [7]. At the same time, and according to the experience with the SARS outbreak in 2003, knowledge and attitudes of epidemics might coincide with a certain level of anxiety or stress among people that might have negative consequences on the prevention and control of the outbreak [8].

As part of Iraq, the Kurdistan Region has also experienced an increasing number the COVID-19 cases. As of the first week of April 2020, the confirmed COVID-19 cases exceeded 200, including two deaths. A variety of control measures were adopted by the Kurdistan Regional Government to mitigate and contain the spread of this disease. The main measures included flight suspension, cross-border activity limitation, 
closure of all schools and universities, suspension of work in all public institutions. These were followed by imposing a curfew in all governorates, quarantining all contacts of the infected people, and community screening, especially in areas where COVID-19 cases were discovered [9].

The efforts to mitigate the transmission of infectious diseases or epidemics are more effective at the early stage of the outbreak. Collecting data on the risk perception and behavioral response of the ordinary people towards the disease can contribute to the health policymakers' understanding of the future development or spread of the disease in the community [10].

Understanding the public perception and behavior towards the spread of COVID-19 can help in mitigating the transmission of the infection. Therefore, this aimed to assess the perspectives of the people towards the coronavirus disease, especially concerning the seriousness of the disease, adherence to protective measures, the effectiveness of the imposed government measures, and people's ability to avoid the infection.

\section{Methods}

\section{Design}

Q-methodology combines both qualitative and quantitative methods to provide a scientific base for studying subjectivity and preference in a systematic way. The method characterizes shared perspectives of different groups of individuals $[11,12]$. The method involves the preparation of a set of statements about a topic that will be rank-ordered by respondents on a quasi-normal distribution based on their viewpoints. Then, the individual viewpoints (or rankings) will be subjected to factor analysis $[11,13]$.

\section{Setting and participants}

This study was conducted in Erbil, Iraqi Kurdistan Region. In Q-methodology studies, the selection of participants should be based on maximizing the representation of a wide range of views [14]. We aimed to involve individuals from different educational, social, and economic status and having some insights about the study topic. Thus, the participants were selected purposively and included both males and females, singles and married and from different age groups, and different educational, social, and economic levels. A sample of 40 participants was selected to participate in the study.

\section{Statements}

A comprehensive review of literature, media reports, and social media posts was conducted to identify the main aspects and the issues about COVID-19 in Iraqi Kurdistan Region. As a result, 67 statements related to COVID-19 were extracted.

Two researchers reviewed these 67 statements for similarities and differences. They discarded the repeated statements, merged those close similarity, and deleted those with polar opposite views. 
Statements representing different aspects of the impact of COVID-19 on the life of people and different perceptions and uncertainties around it were selected. In the end, 41 statements were selected.

Then, the 41 selected statements were translated to the Kurdish language. A native Kurdish speaker who was fluent in the English language validated the translation by back-translation of the Kurdish statements into the English language. We numbered the 41 statements in the Kurdish language randomly. Then, a quasi-normal distribution with nine piles and 41 cells (Q-grid) was created (Fig. 1). The final data collection tools of the study included the list of statements, the Q-grid, and a number of questions about the socio-demographic characteristics of the participants.

\section{Data collection}

Data for this study were collected in late March 2020. The participants were contacted by phone, and the purpose of the study was explained to them before providing participation consent. The survey tool was sent to the participants by email. We provided clear instructions to each participant by email and by phone contact. We asked the participants to sort the statements into the Q-grid with nine piles, ranging from - 4 (least agree) to +4 (most agree), according to the viewpoint towards different aspects of COVID19. The participants read the statements and distributed them to the Q-grid cells. The completed survey tool was returned to the researcher by email. The Research Ethics Committee of Hawler Medical University reviewed and approved this study.

\section{Data analysis}

We used the PQMethod 2.35 program for data analysis [15]. Extracting the prominent common viewpoints was based on centroid factor extraction and varimax rotation. We extracted the viewpoints that represented at least two defining sorts with eigenvalues larger than one [16]. We adopted a conservative significance level $(P<0.01)$ for factor loading. A factor loading of $0.403(2.58 \times 1 \sqrt{ } \mathrm{n}$, where $\mathrm{n}=$ the number of statements) or above on a given viewpoint constituted significant loading [17]. We tested different viewpoint solutions to get the most meaningful, consistent, and coherent viewpoints.

The viewpoints obtained represent the sorts made by the participants who have responded in a potentially similar way. We interpreted each viewpoint subjectively through examining the characterizing and the distinguishing statements. Characterizing statements include the statements with a rank value of $+4,+3,-3$, or -4 . On the other hand, distinguishing statements include the statements with a score on a viewpoint significantly different from their score on the other viewpoints [11]. The last step involved developing a conceptual interpretation to define and summarize the endorsed viewpoints.

\section{Results}

The mean $\pm S D$ age of the 40 respondents was $39.9 \pm 15.9$ years (range 17-68). Most of the respondents were females (65\%), married (65\%), employed (70\%), and having a college degree $(50 \%)$. Details of the socio-demographic characteristic are shown in Table 1. 
Table 1

Socio-demographic characteristics of the respondents.

\begin{tabular}{|lll|}
\hline Characteristic & No. & $\%$ \\
\hline Gender & & \\
Male & 14 & 35 \\
Female & 26 & 65 \\
\hline Age (years) & & \\
\hline$<30$ & 13 & 32.5 \\
\hline $30-39$ & 12 & 30 \\
\hline$>40$ & 15 & 37.5 \\
\hline Marital status & & \\
\hline Single & 14 & 35 \\
\hline Married & 26 & 65 \\
\hline Educational level & & \\
\hline Primary school & 3 & 7.5 \\
\hline Secondary school & 8 & 20 \\
\hline Diploma & 4 & 10 \\
\hline College & 20 & 50 \\
\hline Higher education & 5 & 12.5 \\
\hline
\end{tabular}

Analysis of the respondents' Q-sorts resulted in three distinct viewpoints (a three-factor solution), accounting for $38 \%$ of the variance. Table 2 shows the statement scores for each viewpoint. Of the 41 statements included in the set, 27 statements were ranked statistically significantly differently $(P<0.01)$ between the three viewpoints, and seven statements were ranked similarly in the three viewpoints. The remaining seven statements ranked differently among the three viewpoints, but not to a statistically significant level. 
Table 2

Rank scores of statements for views on the COVID-19 risk, protective behavior and prevention measures

\begin{tabular}{|c|c|c|c|c|}
\hline \# & Statement & $\begin{array}{l}\text { View } \\
1\end{array}$ & $\begin{array}{l}\text { View } \\
2\end{array}$ & $\begin{array}{l}\text { View } \\
3\end{array}$ \\
\hline 1 & $\begin{array}{l}\text { Borders are poorly controlled as infected travelers with COVID-19 can } \\
\text { get into Kurdistan without examination or quarantine. }\end{array}$ & $-2^{\star}$ & $-1 *$ & $+2^{\star}$ \\
\hline 2 & Emergency services are not well prepared to contain the disease. & $-1 *$ & $+3^{*}$ & $+2^{*}$ \\
\hline 3 & Hand sanitizers should be made available in all public places freely. $\dagger$ & +1 & +3 & +2 \\
\hline 4 & $\begin{array}{l}\text { Health education about the disease is provided adequately in places of } \\
\text { work. }\end{array}$ & +1 & +2 & $-3^{*}$ \\
\hline 5 & I always cover my mouth and nose with my bent elbow or tissue. & 0 & 0 & $3 *$ \\
\hline 6 & $\begin{array}{l}\text { If I feel ill, I will hesitate to go to hospital fearing of quarantine of } \\
\text { myself and my family. }\end{array}$ & $-4^{*}$ & 0 & -1 \\
\hline 7 & $\begin{array}{l}\text { I always watch the NEWS and social media in order to be updated } \\
\text { about the disease. }\end{array}$ & $+1^{\star}$ & $+3^{*}$ & $+3^{*}$ \\
\hline 8 & $\begin{array}{l}\text { It is easy for people to change behavior to follow preventive measures } \\
\text { (avoid touching mouth, eyes, nose, avoid handshake, frequent } \\
\text { handwashing) }\end{array}$ & 0 * & $+3^{*}$ & $-3^{*}$ \\
\hline
\end{tabular}

9 I am extremely worried of getting this disease and die from it.

$-2^{\star}+2^{\star}-4^{\star}$

10 It was a wise decision to suspend school during the outbreak.t

$+4+4+4$

11 People still cannot avoid spitting on the floor.

$0 * \quad-2^{*}+4^{*}$

12 Media makes the COVID-19 much bigger issue than as it is.

$-3 *+1+1$

13 Adequate necessary laboratory investigations are available at governmental hospitals.

14 I still have not totally avoided traditional greetings such as hand shaking and kissing.

15 Ordinary people are not well aware of preventive measures.

$-2-1 *-2$

16 Closing borders is not an effective measure to prevent the spread of the disease

17 I bought enough masks to protect myself and others from the disease. $†$

18 I am not with suspending all religious gatherings (Friday or Sunday prayers, paying condolences).

19 People do not take the disease seriously.

$+1+1+2^{*}$

* Distinguishing statement significant at $<0.01$.

† Consensus statement. 


\begin{tabular}{|c|c|c|c|c|}
\hline \# & Statement & View & $\begin{array}{l}\text { View } \\
2\end{array}$ & $\begin{array}{l}\text { View } \\
3\end{array}$ \\
\hline 20 & I clean and wash my hands regularly. & +2 & +2 & +3 \\
\hline 21 & People seriously take and follow the preventive measures & $0 *$ & $+1^{\star}$ & $-2^{\star}$ \\
\hline 22 & People follow well the curfew measures & -2 & -1 & $1^{*}$ \\
\hline 23 & I practice my worships more in order to avoid the disease. & +3 & +2 & $-1^{*}$ \\
\hline 24 & People use face masks unnecessarily. $\dagger$ & -1 & 0 & 0 \\
\hline 25 & I started to eat healthier food and do exercise to increase immunity & $+1^{*}$ & -1 & 0 \\
\hline 26 & Relying on God will help me to avoid the disease. & $+2^{*}$ & $+4^{*}$ & $0 *$ \\
\hline 27 & I stay at home if I begin to feel unwell. & $-1 *$ & 0 & $+2^{*}$ \\
\hline 28 & I have restricted visiting relatives and social gatherings. t $^{-}$ & -2 & -1 & -2 \\
\hline 29 & $\begin{array}{l}\text { I think the government can take appropriate measures to overcome the } \\
\text { disease from spreading. }\end{array}$ & +3 & +1 & $+1^{*}$ \\
\hline 30 & We stored enough food to avoid food crisis. $t$ & +1 & 0 & -1 \\
\hline 31 & I think traveling within cities should not have been suspended. $\dagger$ & -3 & -3 & -2 \\
\hline 32 & If I get the disease, I try some home or natural remedies. & $-1 *$ & -4 & -3 \\
\hline 33 & I think warm weather will stop the outbreak of COVID-19. & 0 & $-2^{*}$ & 0 \\
\hline 34 & I told my family about the importance of frequent hand washing. & $+3^{*}$ & +2 & +1 \\
\hline 35 & I would avoid crowded areas. & $+3^{*}$ & 0 & +1 \\
\hline 36 & $\begin{array}{l}\text { I would be able to avoid the infection by proper and frequent hand } \\
\text { hygiene. }\end{array}$ & $+2^{\star}$ & $-1 *$ & $0 *$ \\
\hline 37 & $\begin{array}{l}\text { I would limit my activities outside such as dining at restaurants or } \\
\text { cafés, going to picnics. }\end{array}$ & $+4^{*}$ & $-3^{*}$ & $0 *$ \\
\hline 38 & I avoid people who cough/sneeze & $+2^{*}$ & $-2^{*}$ & $-1 *$ \\
\hline 39 & $\begin{array}{l}\text { I significantly reduced the number of contacts per day (less than } 1 \\
\text { meter) }\end{array}$ & $+2^{*}$ & $-3 *$ & $0 *$ \\
\hline 40 & I am very worried that my relative and family will get this disease & $0 *$ & $-4^{*}$ & $-2^{*}$ \\
\hline 41 & $\begin{array}{l}\text { This infection is not a serious one and nothing more than common } \\
\text { cold and influenza }\end{array}$ & -1 & $-3^{*}$ & -1 \\
\hline \multicolumn{5}{|c|}{ * Distinguishing statement significant at $<0.01$} \\
\hline & ensus statement. & & & \\
\hline
\end{tabular}


The three viewpoints were defined by 30 respondents (75\%), whereas six respondents did not load significantly on any of the viewpoints, and four respondents were confounded by loading significantly on both viewpoints.

Three different viewpoints and one consensus viewpoint were identified (Table 2). The first viewpoint was labeled as confidence and obedience to protective measures, the second viewpoint was labeled as apprehensiveness and noncompliance, and the third viewpoint was labeled as people's inattentiveness.

\section{Viewpoint 1 - Confidence and obedience to protective measures}

Viewpoint 1 accounted for $13 \%$ of the total variance. The Q-sorts of 11 respondents defined this viewpoint. Exemplars of this viewpoint included eight females and three males; four singles and seven married; eight employed, two students and one not employed; two with secondary school education, seven with college degrees, and two with postgraduate degrees.

Respondents holding the first viewpoint strongly emphasized their compliance with the main protective measures, including limitation of activities outside the home $(37 ;+4$ (statement 37 ; score +4$)$ ), avoiding crowded areas $(35 ;+3)$, reducing the number of contacts $(39 ;+2)$, avoiding people who cough/sneeze (38; $+2)$, eating healthier food and doing exercise to increase immunity $(25 ;+1)$, and having told the family member about the importance of frequent hand washing $(34 ;+3)$. Hesitation to go to the hospital fearing of quarantine $(6 ;-4)$ and staying at home if feeling unwell $(27 ;-1)$ were considered less important by this group, which might indicate seeking healthcare for any illness.

These respondents stressed the seriousness of this disease as the issue of having the media making the COVID-19 much bigger issue than it is was least important for them $(12 ;-3)$. However, always watching the NEWS and social media to be updated about the disease was considered less important by this group in comparison to the other two groups $(7 ;+1)$. These respondents were more worried that their relatives and families might get this disease $(40 ; 0)$. However, they thought that they are able to avoid the infection by proper and frequent hand hygiene $(36 ;+2)$. They indicated that they practice their worship more in order to avoid the disease $(23 ;+3)$.

This group of respondents strongly believed in the effectiveness of the government's measures against the COVID-19 outbreak. They thought that the government could respond appropriately to prevent the spread of the infection $(29 ;+3)$. They least agreed with the statements of having the emergency services being not well prepared to contain the disease $(2 ;-1)$, borders are poorly controlled for infected travelers with the COVID-19 who can get into Kurdistan without examination or quarantine $(1 ;-2)$ and closing borders is not an effective measure to prevent the spread of the disease $(16 ;-3)$.

\section{Viewpoint 2 - Apprehensiveness and noncompliance}


Viewpoint 2 accounted for $14 \%$ of the total variance. The Q-sorts of 12 respondents defined this viewpoint. Exemplars of this viewpoint included ten females and two males; eight married and four singles; eight employed, two students and two not employed; one with primary education, two with secondary education, three with a diploma, and six with college.

The respondents holding this viewpoint looked extremely worried about the disease and had concerns about the government measures against COVID-19. They revealed that they were anxious about getting this disease and die from it $(9 ;+2)$, believed that relying on God will help in avoiding the disease $(26 ;+4)$ and were always watching the NEWS and social media in order to be updated about the disease $(7 ;+3)$. They did not believe that this infection is not a serious one $(41 ;-3)$ and that warm weather will stop the outbreak of COVID-19 $(33 ;-2)$. They did not believe that they can avoid the infection by proper and frequent hand hygiene $(36 ;-1)$. However, they were not much worried that their relatives and families might get this disease $(40 ;-4)$.

This group of respondents believed that the emergency services were not well prepared to contain the disease $(2 ;+3)$, and closing borders was not an effective measure to prevent the spread of the disease $(16 ;+1)$. They less agreed than the other groups that the government can take appropriate measures to overcome the disease from spreading $(29 ;+1)$. They had less agreement than the other groups about the availability of adequate necessary laboratory investigations are available at governmental hospitals (13; $-1)$.

This group of respondents believed that it is easy for people to change behavior to follow preventive measures $(8 ;+3)$ and that people seriously take and follow the preventive measures $(21 ;+1)$. They did not believe that people still cannot avoid spitting on the floor $(11 ;-2)$. However, on a personal level, they appeared not to be able to follow the preventive measures. They least agreed with having a reduced number of contacts (39; -3), limited activities outside the home (37; -3), and avoided people who cough/sneeze (38;-2).

\section{Viewpoint 3 - People's inattentiveness}

Viewpoint 3 accounted for $11 \%$ of the total variance. The Q-sorts of seven respondents defined this viewpoint. Exemplars of this viewpoint included five males and two females; five married and two singles; five employed, one student and one not employed; two with primary education, one with secondary education, two with a college education, and two with postgraduate education.

The participant holding this viewpoint emphasized the lack of awareness and adherence to protective measures by the people. They believed that people still cannot avoid spitting on the floor $(11 ;+4)$, ordinary people are not well aware of preventive measures $(15 ;+3)$, people do not take the disease seriously $(19 ;+2)$. They least agreed that it is easy for people to change behavior to follow preventive measures $(8 ;-3)$, health education about the disease is provided adequately in places of work $(4 ;-3)$, and people seriously take and follow the preventive measures $(21 ;-2)$. However, they thought that people follow well the curfew measures $(22 ;+1)$. They indicated that they follow some protective measures such 
as covering mouth and nose with bent elbow or tissue $(5 ;+3)$ and staying at home if feeling unwell $(27$; $+2)$.

They had some concerns about the government's preventive measures as they believed that borders are poorly controlled with infected travelers able get into Kurdistan without examination or quarantine $(1 ;+2)$ and least agreed about the ability of the government to take appropriate measures to overcome the disease from spreading $(29 ;+1)$.

They least agreed with being extremely worried about getting this disease and dying from it $(9 ;-4)$. In comparison with other groups, they less agreed with relying on God to help in avoiding the disease $(26 ; 0)$ and did not agree with having practiced more worships to avoid the disease $(23 ;-1)$. However, they revealed that they always watch the NEWS and social media in order to be updated about the disease ( 7 ; $+3)$.

\section{Consensus}

There was a general agreement among the three groups of respondents on a number of aspects of COVID-19. They firmly believed that suspending schools during the outbreak was a wise decision $(10 ;+4$, $+4,+4$ (statement 10 ; view $1:+4$, view $2:+4$, view $3:+4$ ). They also believed that hand sanitizers should be made available in all public places freely $(3 ;+1,+3,+2)$. There was some agreement on buying enough masks to protect themselves and others from the disease $(17 ; 0,+1,+1)$. There was some neutral belief about the unnecessary use of face masks by the people $(24 ;-1,0,0)$ and storing enough food to avoid food crisis $(30 ;+1,0,-1)$. The three groups considered suspending the travel among cities $(31 ;-3,-3$, $-2)$ and restricting visits to relatives and social gatherings $(28 ;-2,-1,-2)$ less important.

\section{Discussion}

The current study revealed various patterns of viewpoints regarding the COVID-19 outbreak in Iraqi Kurdistan Region. Individuals from different socio-demographic backgrounds participated in this study as they were thought to give representative viewpoints. This explorative study identified three viewpoints reflecting distinctive perspectives of participants around different aspects of the COVID-19 disease.

The first viewpoint reflected the perspective of accepting government measures as an effective strategy to control and overcome the disease. Also, respondents holding this viewpoint believe that the disease is a serious one, and they were adherent to preventive measures. For example, they mostly agreed with the statements of limiting activities outside the home, avoiding crowded areas and people who cough or sneeze and reducing the number of contacts.

Respondents holding this viewpoint share common beliefs and attitudes with people dealing with infectious respiratory diseases [18]. Their educational background could explain one of the reasons that this group of respondents complies with protective measures as all the respondents in this group were graduated from secondary school and above. Several studies identified that those individuals with higher education were more likely to adopt protective measures and behaviors [19, 20]. 
Additionally, respondents holding viewpoint 1 agree that this disease is serious, and thus their risk perception might be high. Many studies documented the relationship between the perceived risk and engagement in protective measures. For instance, in cases where the higher the risk perception is, people's behavior towards applying protective measures increases [20,21].

Respondents holding viewpoint 1 showed dissimilarity to those in viewpoint 2 and viewpoint 3 , in terms of believing in the effectiveness of government measures since they least agreed with the statement, "emergency services are not well prepared to contain the disease." The Iraqi KRG implemented restrictive measures in order to contain the outbreak. For example, by the end of February, the government decided to suspend all schools and universities in the region. This was followed by declaring a public holiday for the rest of the government entities except for some sectors such as health and law enforcement departments. Simultaneously, the entire religious and public gatherings were suspended, and lastly, lockdown across the region was declared, which is still ongoing [9]. These measures are seriously taken in order to flatten the epidemic curve as it was documented that the more the number of transmissions is reduced, the flatter and longer the curve will be [22].

In addition, the KRG follows the strategy of quarantine for those who had a history of travel from outside Iraq, contact tracing and surveillance in order to control and treat the infected individuals with COVID-19. Studies have shown that by using public health measures (isolation, tracing, and quarantine), such contagious outbreaks can be controlled [23-25]. The KRG implementing these measures in the early stage of the disease is quite crucial since the healthcare infrastructure in the region is insufficient and still developing, and without these measures, a catastrophe might have happened.

In addition, the findings indicate that respondents in this group would seek healthcare advice for any illness as they least agreed to the statement, "If I feel ill, I will hesitate to go to the hospital fearing of quarantine of myself and my family." Also, they thought that by practicing proper and frequent hand washing, they would be able to avoid the infection. The majority of health authorities worldwide recommend that frequent hand washing and social distancing can reduce the chance of getting COVID19 infection [26-28].

Although respondents holding viewpoint 2 did not consider this infection as a serious one, they were extremely worried about getting the disease and eventually dying from it. In addition, they thought that this disease can not be avoided by frequent and proper hand hygiene. It was interesting to notice how respondents do not take appropriate preventive measures despite being worried about getting the disease. For example, they did reduce the number of contacts, limit activities outside the home, and avoid people who cough or sneeze. Such kind of thinking or behaving among people is quite intimidating in the community as no matter how the government applies restrictive measures if people's thinking and behaviors are not in favor of applying protective behaviors, the situation cannot be controlled [22, 29].

Previous studies suggested that levels of worry or anxiety about previous pandemics such as influenza $\mathrm{H} 1 \mathrm{~N} 1$ (in 2009) were linked to compliance with government and health recommendations [10, 21]. This is 
in disagreement with our finding as although respondents holding viewpoint 2 were extremely worried about getting the disease, they were not adhering to protective measures.

In addition, our finding showed that respondents holding viewpoint 2 believed that the emergency services were not well prepared to contain the disease and that closing borders was not an effective strategy to prevent the spread of the infection. However, previous studies indicated that confidence in the ability of the government's measures to control the spread of the disease was related to health recommendation compliance [30]. Previous studies have indicated that those people who have higher trust and confidence in the government's strategy in handling the situation were more likely to comply with their recommendation [21,31].

Respondents in viewpoint 3 indicated that they follow some protective measures to avoid getting the infection. However, their main concern was that people are unaware of preventive measures and are nonadherent to protective measures. In contrast to respondents' perspectives in viewpoint 2, they believed that people cannot avoid some behaviors yet. Changing behavior is not straightforward, and it can be an unsteady process [32].

Similar to respondents in viewpoint 2, this group of people had some concern regarding the government's ability to take appropriate preventive measures. However, they were not worried about getting the COVID19 and dying from it. In comparison with other respondents in viewpoint 1 and viewpoint 2, these respondents least agreed that relying on God helps them to avoid the disease. Also, practicing more worship to avoid the disease seemed to be unimportant by these people.

It is remarkable to notice such diverse perspectives and attitudes among this group of respondents, especially regarding people's unawareness and incompliance of public health recommendations. This requires health authorities to apply different means in order to disseminate information and educate people about applying protective measures.

Interestingly, the respondents holding the three viewpoints had a general agreement around a number of aspects of the COVID-19 disease. There was a strong consensus regarding the concept of suspending schools during the outbreak as a wise decision. A review examining the various aspects of school closure as a public health policy identified that school closure is usually suggested for mitigating the pandemics [33]. However, when such decisions have to be made, officials and authorities must plan to alleviate the undesirable features of the closure.

There was also a general consensus regarding the availability of hand sanitizers in all public places freely. In fact, following the emergence of the outbreak in Kurdistan region, most of the public places like supermarkets and hospitals have provided hand sanitizers for their consumers, in order to reduce the spread of the infection.

There was also some agreement among the three groups of respondents about buying enough masks to protect themselves and others from the disease. However, they had a neutral view of the unnecessary use 
of face masks by the people. The recommendations about when and who to use a face mask are somehow controversial. WHO only recommends the use of face masks in specific cases; for instance, those people who feel unwell having cough, fever, and difficulty breathing should wear a mask. Also, if a healthy person taking care of a suspected person with COVID-19, then s/he should wear a mask [26]. Some provinces of China have imposed a policy of compulsory face masks in public places [34]. Nevertheless, recently, the Centers for Disease Control and Prevention recommends using cloth face masks to assist in reducing the spread of COVID-19 in public areas where it is hard to adhere to social distancing [35].

This study, through its explorative nature, revealed a range of distinct perspectives of individuals residing in Kurdistan region toward the COVID-19. The variety of perspectives presents here in this study, in fact, reflects the variety of views that exist among people in Iraqi Kurdistan region regarding the COVID-19. By applying Q-methodology, this study helped in understanding people's views and attitudes in relation to different aspects of COVID-19. However, the study findings cannot be generalized as the sample in Qstudies usually includes a small number of respondents [36]. Thus, further research exploring people's views about COVID-19 on a greater scale and in more in-depth ways might be necessary, especially taking those perspectives who are not adherent to the protective measures.

\section{Conclusion}

By determining disagreement and consensus among people, three different viewpoints on COVID-19 were uncovered. The primary aspects distinguishing the three viewpoints focus on risk perception, protective behavioral response, and government's preventive measures. The viewpoints were at both extremes of compliance and non-compliance and confidence and apprehensiveness. Risk perception can guide appropriate protective behavior, but not always. For strengthening the preventive measures, and compliance with protective behaviors, different approaches that can address the needs of different groups of people are required. The focus should be on increasing the risk awareness, but at the same time reducing the stress and anxiety associated with COVID-19. Details of justification and effectiveness of the government's preventive measures should be explained to the people in appropriate ways.

\section{Abbreviations}

COVID-19

Coronavirus disease

\section{Declarations}

\section{Ethics approval and consent to participate}


The Research Ethics Committee of Hawler Medical University reviewed and approved this study. Consent was obtained for each participant before participation in the study. All participants were informed about the anonymity and confidentiality of information.

\section{Consent for publication}

Not applicable.

\section{Availability of the data and materials \\ The Q-Method dataset used for the current study is available in the Mendeley datasets repository (doi: 10.17632/wsbt3spbbc.1).}

\section{Competing interests}

The authors declare that they have no competing interests.

\section{Funding}

Not applicable.

\section{Author's contributions}

KMA participated in conceiving and designing the study, participated in data collection, contributed to drafting the manuscript, and read and approved the final manuscript. KIM participated in designing the study and data collection, contributed to drafting the manuscript, and read and approved the final manuscript. SAS participated in designing the study, contributed to drafting the manuscript, and read and approved the final manuscript. NPS participated in conceiving and designing the study, carried out data analysis, edited, and finalized the manuscript.

\section{References}

1. Chan JF, Kok KH, Zhu Z, Chu H, To KK, Yuan S, et al. Genomic characterization of the 2019 novel human-pathogenic coronavirus isolated from a patient with atypical pneumonia after visiting Wuhan. Emerg Microbes Infect. 2020;9:221-36.

2. World Health Organization. Coronavirus. Overview. https://www.who.int/docs/defaultsource/coronaviruse/situation-reports/20200304-sitrep-44-covid-19.pdf?sfvrsn=783b4c9d_23. 
Accessed 25 Mar 2020.

3. Centers for Disease Control and Prevention. Coronavirus disease 2019 (COVID-19). How to protect yourself and others. https://www.cdc.gov/coronavirus/2019-ncov/prevent-gettingsick/prevention.html. Accessed 22 Mar 2020.

4. Brewer NT, Chapman GB, Gibbons FX, Gerrard M, McCaul KD, Weinstein ND. Meta-analysis of the relationship between risk perception and health behavior: The example of vaccination. Health Psychol. 2007;26(2):136-45.

5. Wise T, Zbozinek T, Mechelini G, Hagan CC. Changes in risk perception and protective behavior during the first week of the COVID-19 pandemic in the United States. PsyArXiv. 2020; doi:10.31234/osf.io/dz428.

6. 10.1101/2020.02.18.20024448

Qian M, Wu Q, Wu P, Hou Z, Liang Y, Cowling BJ, et al. Psychological responses, behavioral changes and public perceptions during the early phase of the COVID-19 outbreak in China: a population based cross-sectional survey. MedRxiv. 2020; do:10.1101/2020.02.18.20024448.

7. Ajilore K, Atakiti I, Onyenankey K. College students' knowledge, attitudes and adherence to public service announcements on Ebola in Nigeria: Suggestions for improving future Ebola prevention education programmes. Health Education Journal. 2017;76:648-60.

8. Person B, Sy F, Holton K, Govert B, Liang A. National Center for Inectious Diseases SCOT. Fear and stigma: the epidemic within the SARS outbreak. Emerg Infect Dis. 2004;10:358-63.

9. Kurdistan Regional Government. Situation update. Coronavirus (COVID-19). https://gov.krd/coronavirus-en/situation-update/\#situation-summary. Accessed 27 Mar 2020.

10. Jones JH, Salathe M. Early assessment of anxiety and behavioral response to novel swin-origin influenza A (H1N1). PLoS ONE. 2009;4(12):e8032.

11. van Exel NJA, de Graaf G. Q methodology: A sneak preview. 2005. http://qmethod.org/articles/vanExel.pdf. Accessed 20 Mar 2020.

12. Shinebourne P, Adams M. Q-methodology as a phenomenological research method. Existential Analysis. 2007;18(1):103-16.

13. Smith NW. Current systems in psychology: history, theory, research, and applications. Belmont: Wadsworth; 2001.

14. Cross RM. Exploring attitudes: the case for Q methodology. Health Educ Res. 2005;20(2):206-13.

15. Schmolck P. PQMethod Q methodology analysis program. 2002 http://www.Irzmuenchen.de/ schmolck/qmethod/.

16. Shinebourne P. Using Q method in qualitative research. IJQM. 2009;8(1):93-7.

17. Stainton Rogers R. Q methodology. In Rethinking methods in psychology. Edited by Smith JA, Harre R, Van Langenhove L. Thousand Oaks, CA: Sage; 1995. p. 178-92.

18. Wang C, Pan R, Wan X, Tan Y, Xu L, Ho CS, Ho RC. Immediate psychological responses and associated factors during the initial stage of the 2019 coronavirus disease (COVID-19) epidemic 
among the general population in china. Int J Environ Res Public Health. 2020;17(5):1729.

19. Zhan S, Yang YY, Fu C. Public's early response to the novel coronavirus-infected pneumonia. Emerg Microbes Infect. 2020;9(1):534.

20. Bish A, Michie S. Demographic and attitudinal determinants of protective behaviours during a pandemic: a review. Br J Health Psychol. 2010;15(4):797-824.

21. Rubin GJ, Amlôt R, Page L, Wessely S. Public perceptions, anxiety, and behaviour change in relation to the swine flu outbreak: cross sectional telephone survey. BMJ. 2009;339:b2651.

22. Anderson RM, Heesterbeek H, Klinkenberg D, Hollingsworth TD. How will country-based mitigation measures influence the course of the COVID-19 epidemic? Lancet. 2020;395(10228):931-4.

23. Hellewell J, Abbott S, Gimma A, Bosse NI, Jarvis Cl, Russell TW, et al. Feasibility of controlling COVID19 outbreaks by isolation of cases and contacts. Lancet Glob Health. 2020;8(4):PE488-96.

24. Fraser C, Riley S, Anderson RM, Ferguson NM. Factors that make an infectious disease outbreak controllable. Proceedings of the National Academy of Sciences. 2004;101(16):6146-51.

25. Keeling MJ, Hollingsworth TD, Read JM. The Efficacy of Contact Tracing for the Containment of the 2019 Novel Coronavirus (COVID-19). medRxiv. 2020 Jan 1.

26. WHO. Coronavirus disease (COVID-19) advice for the public. 2020.

https://www.who.int/emergencies/diseases/novel-coronavirus-2019/advice-for-public. Accessed 28 Mar 2020.

27. CDC. How to Protect Yourself \& Others. 2020. https://www.cdc.gov/coronavirus/2019-ncov/preventgetting-sick/prevention.html. Accessed 1 Apr 2020.

28. NHS. Advice for everyone Coronoavirus (COVID-19). 2020.

https://www.nhs.uk/conditions/coronavirus-covid-19/. Accessed 8 Apr 2020.

29. Lau JT, Griffiths S, Choi KC, Lin C. Prevalence of preventive behaviors and associated factors during early phase of the H1N1 influenza epidemic. Am J Infect Control. 2010;38(5):374-80.

30. Tang CS, Wong CY. An outbreak of the severe acute respiratory syndrome: predictors of health behaviors and effect of community prevention measures in Hong Kong, China. Am J Public Health. 2003;93(11):1887-8.

31. Prati G, Pietrantoni L, Zani B. Compliance with recommendations for pandemic influenza H1N1 2009: the role of trust and personal beliefs. Health Educ Res. 2011;26(5):761-9.

32. Bouton ME. Why behavior change is difficult to sustain. Prev Med. 2014;68:29-36.

33. Cauchemez S, Ferguson NM, Wachtel C, Tegnell A, Saour G, Duncan B, Nicoll A. Closure of schools during an influenza pandemic. Lancet Infect Dis. 2009;9(8):473-81.

34. Feng S, Shen C, Xia N, Song W, Fan M, Cowling BJ. Rational use of face masks in the COVID-19 pandemic. Lancet Respir Med. 2020;pii:S2213-2600(20)30134-X.

35. CDC. Use of Cloth Face Coverings to Help Slow the Spread of COVID-19. 2020. https://www.cdc.gov/coronavirus/2019-ncov/prevent-getting-sick/diy-cloth-face-coverings.html. Accessed 9 Apr 2020. 
36. Shabila NP, Ahmed HM, Yasin MY. Assessment of women's perspectives and experiences of childbirth and postnatal care using Q-methodology. East Mediterr Health J. 2015;21(9):647-54.

Figures

\section{Least agree}

Most agree

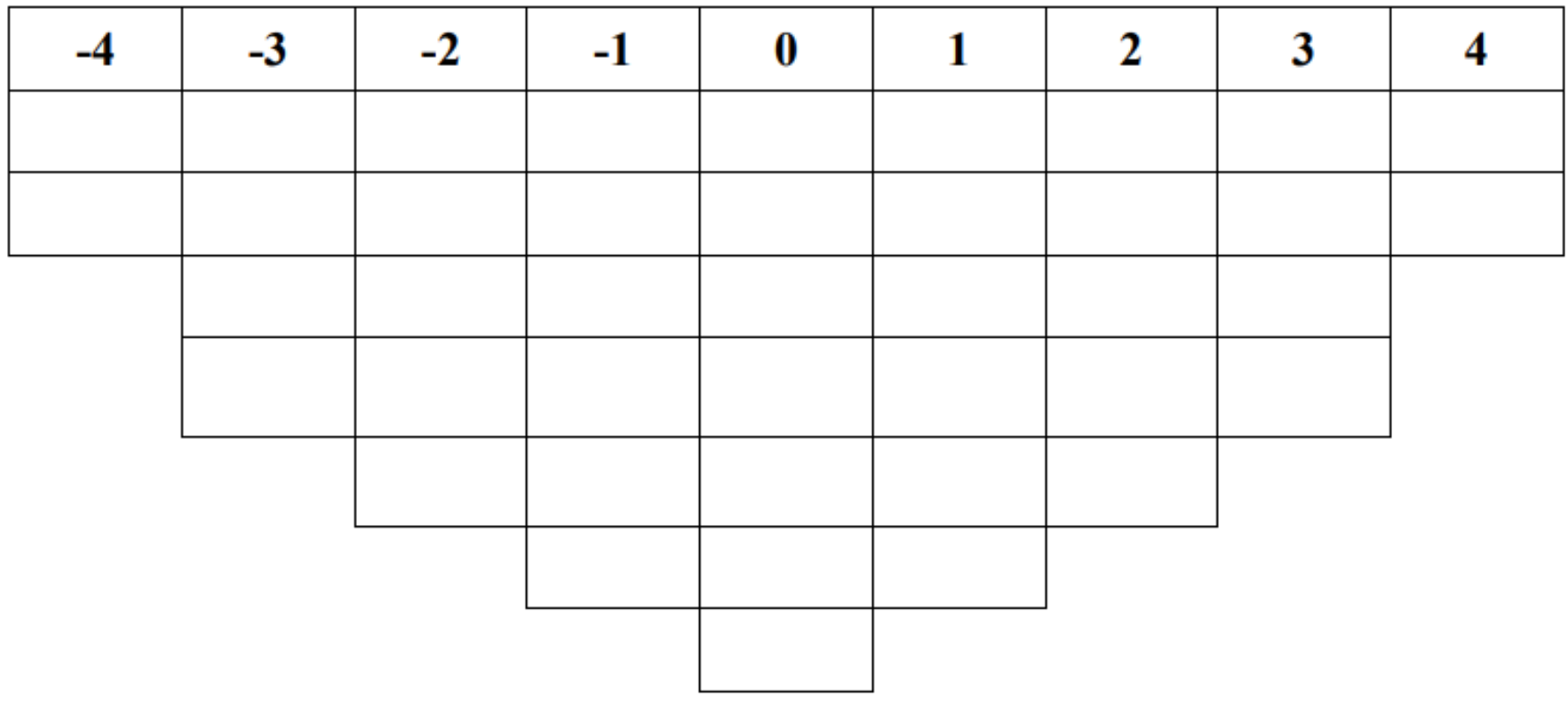

Figure 1

Scoring grid 